\title{
EFFECT OF PTFE ON A CONFINED EXPLOSION OF HMX-BASED THERMOBARIC EXPLOSIVES
}

\section{VPLIV PTFE NA OMEJENO EKSPLOZIJO HMX TERMOBARIČNIH EKSPLOZIVOV}

\author{
Wei Xiao ${ }^{1}$, Ju Huang ${ }^{2}$, Zhiwei Han ${ }^{1}$, Xiaowen Hong ${ }^{3}$, Boliang Wang ${ }^{1 *}$ \\ ${ }^{1}$ Department of Safety Engineering, School of Chemical Engineering, Nanjing University of Science and Technology, \\ No. 200 Xiaolingwei Street, Xuanwu District, Nanjing City, Jiangsu Province, Nanjing 210094, China \\ ${ }^{2}$ Xuzhou University of Technology, Xuzhou, Xuzhou City, Jiangsu Province, Yunlong District Lishui 2, 221018, P. R. China \\ ${ }^{3}$ School of Mechanical Engineering, Nanjing University of Science and Technology, Nanjing, P. R. China \\ Prejem rokopisa - received: 2019-10-24; sprejem za objavo - accepted for publication: 2020-06-17
}

doi:10.17222/mit.2019.239

\begin{abstract}
The confined explosions of HMX-based thermobaric explosives containing PTFE in a $1.43 \mathrm{~m}^{3}$ chamber were investigated to study the oxidising ability of PTFE. This work highlights that the time of converting $\mathrm{Al}$ to $\mathrm{Al}_{2} \mathrm{O}_{3}$ was extended to nearly $200 \mu \mathrm{s}$, based on the optical radiation of $\mathrm{Al}_{2} \mathrm{O}_{3}$. The results that were obtained with a high-speed camera concerning the afterburning reactions to PTFE showed that the duration of the fireball reduced by about $18 \%$. In addition, the total energy, the total impulse and the duration of the oscillation of the shock wave were increased because of PTFE. This work shows that PTFE was an effective oxidizer for an aluminized thermobaric explosive.

Keywords: thermobaric explosive, afterburning reactions, confined explosions, PTFE
\end{abstract}

V zaprtem prostoru oz. komori velikosti $1,43 \mathrm{~m}^{3}$ so avtorji raziskovali eksplozije termobaričnih HMX eksplozivov (angl.: High Melting Explosive), vsebujočih politetrafluoretilen (PTFE) in tako študirali njegovo oksidativno sposobnost. V tem prispevku so avtorji pokazali na osnovi optičnega sevanja $\mathrm{Al}_{2} \mathrm{O}_{3}$, da se čas pretvorbe $\mathrm{Al} v \mathrm{Al}_{2} \mathrm{O}_{3}$ poveča na skoraj $200 \mu \mathrm{s}$. Rezultati, ki se nanašajo na reakcije po vžigu PTFE in so jih zajemali z visokohitrostno kamero so pokazali, da se je čas trajanja ognjene krogle zmanjšal za okoli $18 \%$. Dodatno so ugotovili, da so se zaradi PTFE povečali celotna energija in celotni impulz ter trajanje nihanja udarnih valov. S tem izbranim primerom so avtorji pokazali, da je PTFE učinkovit oksidant aluminiziranih termobaričnih eksplozivov.

Ključne besede: termobarični eksploziv, reakcije po vžigu, zaprte eksplozije, PTFE

\section{INTRODUCTION}

The thermal and pressure effects of aluminized thermobaric explosives would be greatly enhanced with aluminium powder, which releases a great deal of energy when it burns violently. ${ }^{1,2}$ However, the complicated afterburning reactions with aluminium are related to formulations and ambient air. Considering the limited oxygen content in the air, adding oxidants is an effective way to enhance the afterburning reactions and increase the total energy of the explosion. In this case, it is very important and meaningful to study the oxidising ability of oxidants during an explosion.

A review of the published literature showed that AP (ammonium perchlorate) is a high-energy oxidant that is frequently used. AP has a high oxygen content, and its thermal decomposition products (except oxygen) at high temperature can also react with aluminium powder. In 2006, AP was added to improve the oxygen balance of RDX-based aluminized thermobaric explosives to increase the total energy. ${ }^{3}$ Years later, a thermobaric consisting of AP/Al (25/75 or 50/50) was studied. The re-

*Corresponding author's e-mail

boliangwang@163.com (Boliang Wang) sults showed that the quasi-static pressure (QSP) in the chamber was increased, and the aluminium powder was almost completely burnt. ${ }^{4}$ Recently, fluorine-containing materials were studied because the oxidation of $\mathrm{F}$ (fluorine) is stronger than $\mathrm{O}$ (oxygen). Among these materials, PTFE (polytetrafluoroethylene) is highly recommended due to its high fluoride content and stable chemical properties. With the emergence of PTFE/Al as an energetic material, many scholars have studied its chemical properties of thermal decomposition and combustion. $^{5-8}$ However, although PTFE was often used as the binder in aluminized thermobaric explosives, the oxidising properties of PTFE were not realized. Surprisingly, M. L. Chan ${ }^{9}$ found that fluorine-containing materials could promote a metal powder to participate in detonation reactions when he studied a light metallized explosive with PTFE and other fluoro-rubbers as a binder. ${ }^{9}$ Further research of mixed explosives containing Teflon proved that aluminium afterburning was enhanced. ${ }^{10}$ Therefore, PTFE has a certain effect on the afterburning reactions of aluminized thermobaric explosives. Nevertheless, the reactions become complicated because of the addition of PTFE. In the literature available at present, there are few relevant studies, and the afterburning reactions are still not clear. All in all, it is 
necessary to study the effect of PTFE in a confined explosion. In particular, it is of great significance to enhance the oxidation of aluminium powder and increase the total energy. Furthermore, it can enrich the theoretical knowledge of afterburning reactions and guide the design of formulations.

The effect of fireball temperature, fireball duration and pressure are described in detail in this paper with a study of HMX-based thermobaric explosives containing PTFE in a confined chamber. The recorded data from optical spectroscopy based on $\mathrm{Al}_{2} \mathrm{O}_{3}$ is used to calculate the fireball temperature. Furthermore, the features and spherical nature of the fireball are recorded with a high-speed camera to estimate its duration. The reflected pressure histories are recorded with a pressure gauge. The results show that PTFE enhances the afterburning
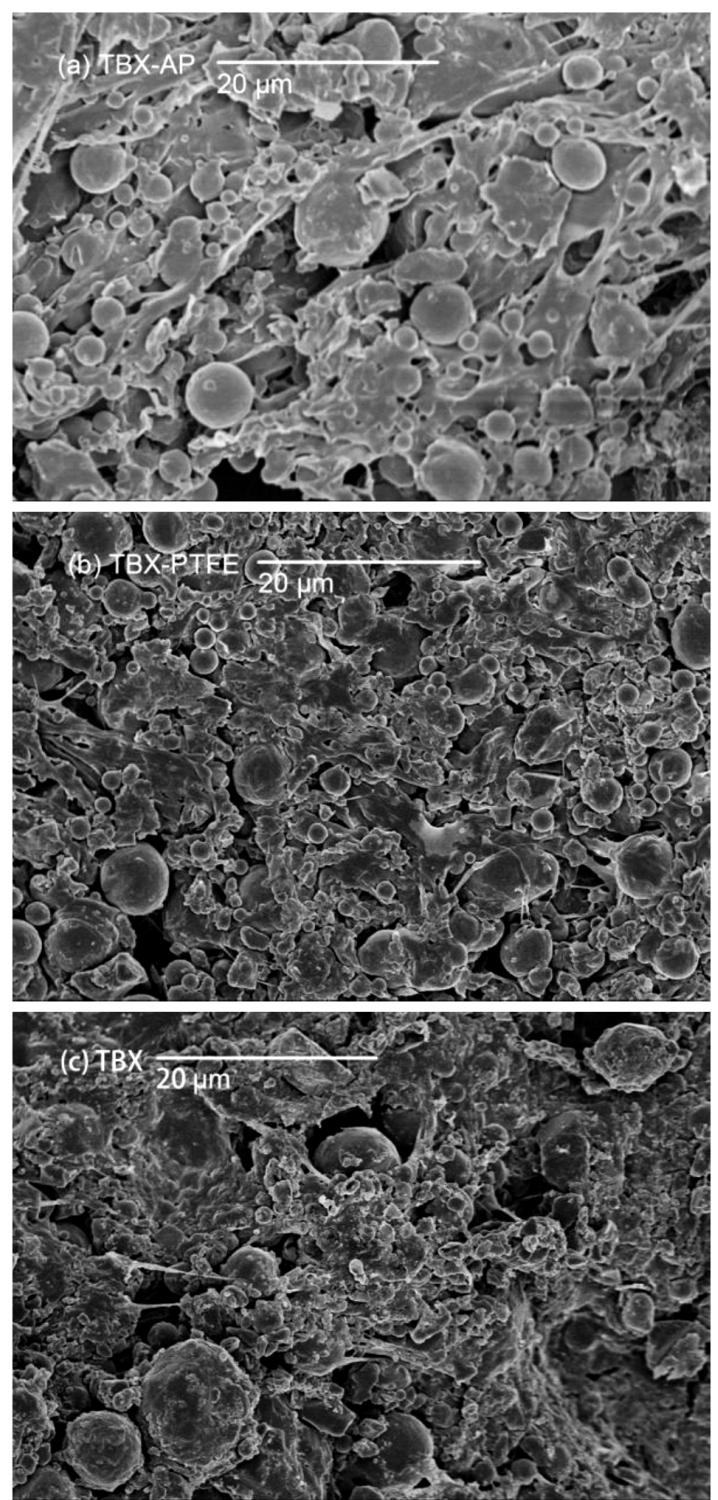

Figure 1: SEM images of the thermobaric particles: a) TBX-AP, b) TBX-PTFE, c) TBX reactions. Finally, this work can contribute to the design of formulations.

\section{EXPERIMENTAL PART}

\subsection{Characteristics of charges}

Three kinds of pressed cylindrical charges containing different components (HMX/Al/oxidizer/binder $49 / 33 / 10 / 8 w / \%$ ) were used in the study. The dried HMX was selected as a high-energy explosive, with a median diameter of about 50-80 $\mu \mathrm{m}$. The added highly active aluminium powder had a spherical shape and a median diameter of $5.4 \mu \mathrm{m}$. To avoid the impact on the experimental results, butadiene series rubber $\left(\left(\mathrm{C}_{4} \mathrm{H}_{6}\right)_{\mathrm{n}}\right)$ without $\mathrm{F}$ (fluorine) was used as a binder and dissolved in ethyl acetate $\left(\mathrm{C}_{4} \mathrm{H}_{8} \mathrm{O}_{2}\right)$ solution. $10 \%$ of the oxidizers of AP (dry powder, with a median diameter of about 20-40 $\mu \mathrm{m}$ ) and PTFE were added to thermobaric explosives named TBX-AP and TBX-PTFE, respectively. PTFE, made by the company of Aladdin, had a median diameter of $50 \mathrm{~nm}$. Besides, $10 \%$ of HMX instead of an oxidiser was added to TBX as a comparative sample. After the components were evenly mixed by the "wet method", 11,12 these energetic granules were pressed for cylindrical charges. Each charge was $100 \mathrm{~g}$, and its dimension was $\phi 40 \times 40 \mathrm{~mm}$.

The morphology and structure of the thermobaric particles were scanned by SEM (scanning electron microscopy), and the SEM images are shown in Figure 1. The interior spaces of the TBX-AP particles were larger than the TBX, probably because of the large diameter of the AP particles. Compared to TBX-AP, TBX-PTFE particles were glued tightly together; because PTFE is a type of fluororubber, it can be used as the oxidizer or binder. However, TBX particles seem more fluffy, and the surface was undulating and uneven.

\subsection{Experimental site}

Experiments were performed in a confined spherical explosion chamber with a volume of $1.43 \mathrm{~m}^{3}$. The chamber, which had good tightness and heat preservation, was made of steel. Its shape and dimensions are shown in Figure 2, and the chamber was provided with two flanges. Small equipment, such as gauges and bullet-proof glass, can be installed on the flanges. In this work, a high-speed camera was used to record the growth of the fireball. The sampling frequency of the high-speed camera was set to 7000 frames per second. Meanwhile, two pressure gauges of PCB and one fibre optic sensor were installed on the other flange. The pressure signals and optical signals during the explosion were obtained by the data acquisition instrument, whose sampling frequency was set at $1 \mathrm{MHz}$. Before the test, the air in the chamber was evacuated by a vacuum pump, and then filled with dry air so that the air pressure reached $0.1 \mathrm{MPa}$. Unfortunately, only about $90 \%$ of the 


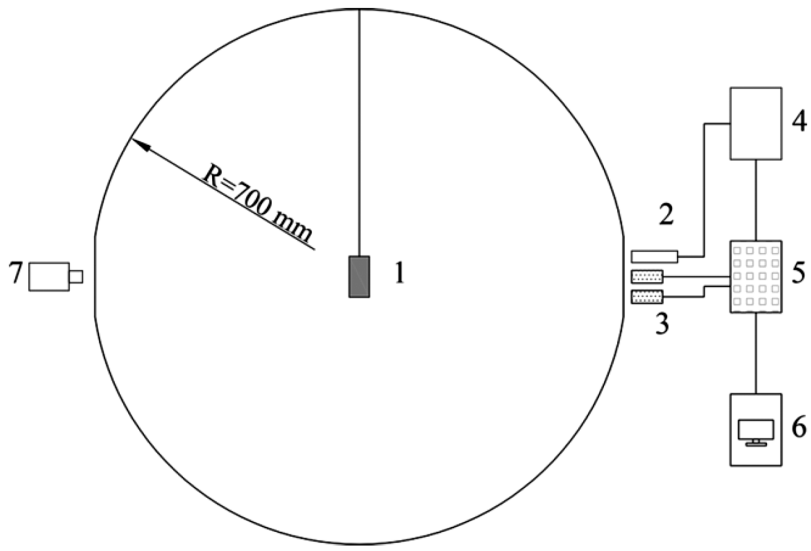

Figure 2: Schematic of the explosion chamber (side view): 1-explosive charge, 2-fibre optic sensor, 3-pressure gauges of PCB, 4-photoelectric converter, 5-data-acquisition instrument, 6-computer, and 7- high-speed camera

air was evacuated due to the large volume of the chamber and the low efficiency of the vacuum pump. According to previous test records, the humidity was less than $10 \%$. Therefore, there was still a small amount of moisture in the air in the chamber during the test. However, the effect of moisture on the test results was not significant. The booster was strapped to one end of the charge and hung in the centre of the chamber. After the test equipment was ready, the detonation of the charge was initiated. Under the same conditions, two parallel experiments were carried out for each group of charges. It is important to keep the lab dark to eliminate interference when the high-speed camera was working.

\section{RESULTS AND DISCUSSION}

\subsection{Temperature of thermobaric explosives}

\subsubsection{Temperature measurement principle}

The components reacted rapidly and violently after the aluminized thermobaric was initiated. The high temperature and pressure of the explosion led to the rapid conversion of $\mathrm{Al}$ to $\mathrm{Al}_{2} \mathrm{O}_{3},{ }^{11}$ which radiated light signals. Based on the continuous spectrum of the $\mathrm{Al}_{2} \mathrm{O}_{3}$ condensed phase, ${ }^{13}$ the temperature measurement system was established to record the light signals in this paper. The relation between the light intensity of condensed phase substances and temperature can be described by Planck's law of radiation

$$
I_{\lambda_{i, T}}=C_{1} \cdot \varepsilon_{\lambda_{i, T}} \cdot \lambda_{i}^{-5}\left[e^{\frac{C_{1}}{e_{\lambda_{i, T}}}}-1\right]^{-1}
$$

Where $I_{\lambda \mathrm{i}, \mathrm{T}}$ is the light intensity, $\varepsilon_{\lambda \mathrm{i}, \mathrm{T}}$ is the emissivity of condensed phase material, $\lambda_{i}$ is the wavelength, $T$ is the absolute temperature, $C_{1}$ is the first radiation constant of $3.74 \cdot 10^{-16} \mathrm{~W} \cdot \mathrm{m}^{2}$, and $C_{2}$ is the second radiation constant of $1.43879 \cdot 10^{-2} \mathrm{~m} \cdot \mathrm{K}$.

Optical signals of $\mathrm{Al}_{2} \mathrm{O}_{3}$ were transmitted by quartz optical fibre to go through the steps of light splitting (one in, five out), filtering and conversion of the photoelectric signal. After that, five sets of voltage signals of different wavelengths were transmitted from the temperature measurement system to the data-acquisition system. Finally, the temperatures were output by calculating with MATLAB.

It was necessary to calibrate the temperaturemeasurement system before it was applied to the tests. First, the explosive products of aluminized thermobaric were collected, and the main product of $\alpha-\mathrm{Al}_{2} \mathrm{O}_{3}$ was found with an XRD (X-ray diffractometer). Then, $\alpha-\mathrm{Al}_{2} \mathrm{O}_{3}$ powders (particle size of $30 \mathrm{~nm}$, purity of $99.99 \%$ ) were heated and the optical signal was recorded by a temperature-measurement system. Then, the proportional relation between the optical signal and the voltage signal was obtained by reverse calculation of the actual heating temperature. The recorded signal for the voltage-time of the TBX-AP charge is shown in Figure 3.

According to the emission spectrum of aluminium particles burning, ${ }^{13,14}$ the radiation intensity of $\mathrm{Al}$ atoms at the wavelengths of $394.4 \mathrm{~nm}$ and $396.2 \mathrm{~nm}$ was abrupt, which was much higher than other wavelengths in this region. Later, near the $500 \mathrm{~nm}$ wavelength, the AlO molecular light intensity was very high. Then from the $600 \mathrm{~nm}$ wavelength, the radiant intensity of the flame began to stabilize. Considering the existing test conditions and performance of the filters, the temperature measurement system was based on 5 wavelengths $(600$, $650,700,750,808) \mathrm{nm}$ of $\mathrm{Al}_{2} \mathrm{O}_{3}$ continuous spectrum to record the light intensity. As can be predicted, the explosive products of this work were mainly $\mathrm{Al}_{2} \mathrm{O}_{3}$, and there were also a small amount of $\mathrm{AlF}_{3}, \mathrm{AlCl}_{3}, \mathrm{AlN}$ and other substances. According to Snelson's research, ${ }^{15}$ the wavelength of $\mathrm{AlF}_{3}$ was outside the spectral range (600-808 nm). In addition, while the non-uniform process leads to non-thermoluminescence, the reaction between $\mathrm{Al}$ and PTFE contributes little to radiation. ${ }^{10}$ Therefore, the impact of a small number of explosive products $\left(\mathrm{AlF}_{3}, \mathrm{AlCl}_{3}\right.$ and $\left.\mathrm{AlN}\right)$ on the light intensity of

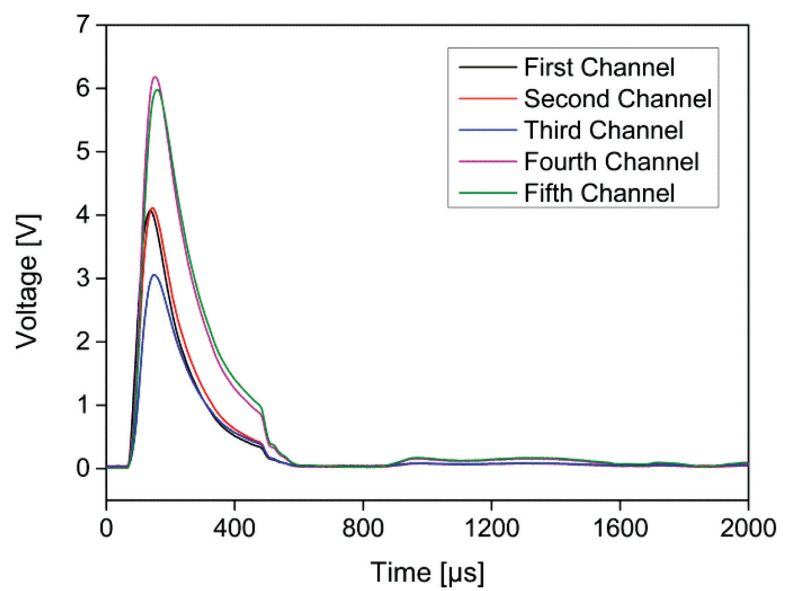

Figure 3: The typical voltage signal varies with time for the TBX-AP charge 
$\mathrm{Al}_{2} \mathrm{O}_{3}$ was slight. The principle, steps, mathematical calculations and correction method of the temperaturemeasurement system were described in detail in a previous study. ${ }^{16}$

\subsubsection{Fireball temperature}

According to the thermobaric characteristics, the explosive procedure can be divided into three stages: detonation, anaerobic combustion and aerobic combustion. ${ }^{17,18}$ During the explosion procedure, the oxidised shell covering the aluminium powder ruptures because of rapid warming and expansion. Then, the active aluminium powder in the oxidised shell can be quickly vaporized and reacts with the detonation products and oxygen to produce $\mathrm{Al}_{2} \mathrm{O}_{3}$. The instantaneous temperature in this paper is obtained based on the light signal of $\mathrm{Al}_{2} \mathrm{O}_{3}$, which is recorded by a temperature measuring system. Therefore, the instantaneous temperature that is contributed from anaerobic combustion and aerobic combustion can be measured. It also indicates that the value and the duration of the temperature are closely related to the oxygen content.

The typical temperature profiles of the charges are shown in Figure 4. There is a similar trend, which first shows a rapid rise, then a rapid decline, and finally fluctuates around a certain value. However, there are significant differences in the peak temperature and cooling rate between formulations. The variation in temperature with time shows that the test results are in line with reality. Therefore, the temperatures of stages I, II and III are discussed and divided by the peak values and the inflection points. The temperature parameters of the two parallel tests are averaged and summarized in Table $\mathbf{1 .}$

Stage I was the increased period of temperature. This stage was mainly the diffusion of detonation products, with aluminium powder scattered and heated, while less air was drawn into the explosive field because of the turbulence effect. The temperature of the charges sharply increased after the optical fibre sensor received the optical signal of $\mathrm{Al}_{2} \mathrm{O}_{3}$. However, the temperatures peak at different times, especially the TBX-PTFE charges, which had a lower slope and took longer (approximately $80 \mu \mathrm{s})$ to reach the peak. The average peak temperature was $2676.8 \mathrm{~K}$, for the $69 \%$ TBX-AP and $76 \%$ TBX. This was related to the highly reactive element $F$ (fluorine) of PTFE. Under high temperature and pressure, the gasified aluminium powders were oxidised by $\mathrm{F}$ and produced $\mathrm{AlF}_{3}$ instead of $\mathrm{Al}_{2} \mathrm{O}_{3}$.

Stage II was the decline period of the temperature in hundreds of microseconds. As more and more air was sucked in, a variety of materials such as $\mathrm{O}_{2}$, aluminium powders, detonation products and thermal decomposition products were rapidly mixed on account of the reflection from the blast waves. The temperature of the TBX-AP and TBX decreased rapidly after reaching the peak, while the TBX-PTFE decreased gradually. After the aluminium powders were continuously gasified, they reacted violently with the detonation products and the oxy- gen, resulting in $600 \mu$ s of afterburning for TBX, as shown in Figure 4. However, TBX-AP at approximately $457 \mu \mathrm{s}$ had an even shorter afterburning time. The thermal decomposition products of AP participated in the chemical reaction to aluminium, and the temperature further increased because aluminium powders were accelerated. In contrast, TBX-PTFE charges had a long afterburning time of $713 \mu \mathrm{s}$. This result indicated that the afterburning reactions were prolonged with the addition of PTFE. These differences were attributed to the small molecules, such as $\mathrm{C}_{2} \mathrm{~F}_{4}$ (tetrafluoroethylene), resulting from the decomposition of PTFE. The F oxidised some of the aluminium powders first so that the reactions to aluminium and oxygen were delayed. Compared to TBX, the TBX-PTFE charges had enough oxygen to react with the rest of the aluminium and produced $\mathrm{Al}_{2} \mathrm{O}_{3}$. Therefore, the duration and temperature of the afterburning reactions were higher than those of the TBX. In addition, the inflection point of the temperature appeared at a later time.

Stage III was the period after the inflection point when the temperature continued to fall to the baseline. The reason for the appearance of the inflection point was that the oxygen in the explosive field was exhausted. In addition, oxygen could no longer carry out the oxidation reaction, resulting in a dramatic drop in temperature. After that, it was mainly the reaction to aluminium powders with some intermediate products. At the same time, a small number of low oxides $\left(\mathrm{Al}_{2} \mathrm{O}\right.$, etc. $)$ were converted to $\mathrm{Al}_{2} \mathrm{O}_{3}$. Figure 4 shows that the PTFE reduced the initial temperature of the TBX-PTFE charges. Hence, the gasification of aluminium powders was similarly reduced. In addition, the chemical reactions of the aluminium powders with oxygen were also delayed.

By comparison, the time it took the $\mathrm{Al}$ from the TBX-PTFE to convert to $\mathrm{Al}_{2} \mathrm{O}_{3}$ was nearly $200 \mu$ s longer than that of the others. Moreover, the fireball temperature stayed above $1000 \mathrm{~K}$ for a longer period, and it was beneficial to the aluminium afterburning. Additionally, the sustained high temperature would cause more damage to the targets. There were many reactions involved in the combustion process of aluminium afterburning, and they were complicated and ambiguous. However, according to the law of temperature, PTFE had a certain influence on afterburning reactions, especially on its duration.

Table 1: Average value of temperature parameters.

\begin{tabular}{|l|c|c|c|c|}
\hline \multirow{2}{*}{ Name } & \multicolumn{2}{|c|}{ Temperature $(\mathrm{K})$} & \multicolumn{2}{c|}{ Time $(\mu \mathrm{s})$} \\
\cline { 2 - 5 } & Peak Point & $\begin{array}{c}\text { Inflection } \\
\text { Point }\end{array}$ & Stage I & Stage II \\
\hline TBX-AP & 3866.9 & 1466.5 & 78.5 & 457 \\
\hline TBX-PTFE & 2676.8 & 1658.3 & 84 & 713 \\
\hline TBX & 3466.5 & 1517.9 & 65 & 450 \\
\hline
\end{tabular}




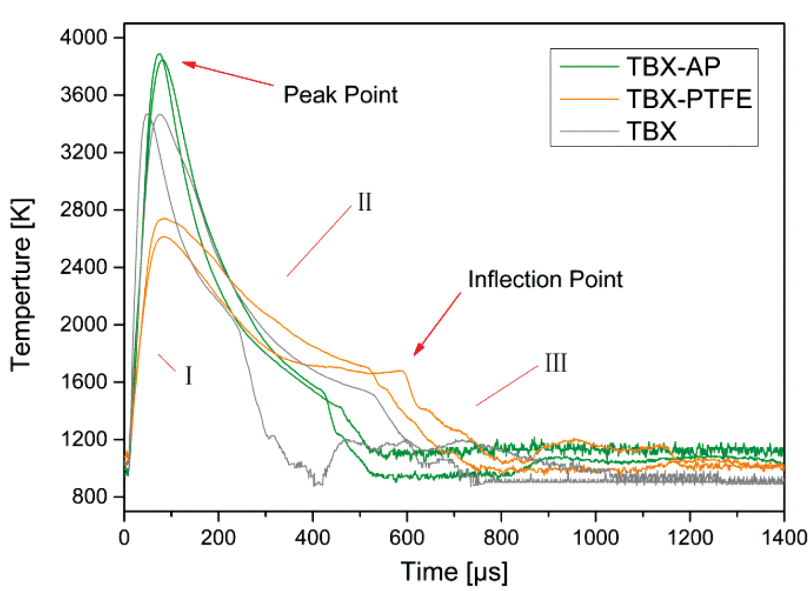

Figure 4: Typical temperature profiles of the charges

\subsection{Fireball duration}

The explosive procedure of charges was recorded by a high-speed camera in the presented work. The sampling frequency of the high-speed camera was set to 7000 frames per second, which meant that each image was approximately $143 \mu$ s apart. Considering the many pictures of the fireball recorded, representative fireball pictures were selected as the object for discussion. The duration and spatial distribution of the fireballs are shown in Figure 5. It is clear that the fireball obvious features of light and dark. As the fireball continued to expand, the light grew brighter and brighter until it was a dazzling white light. Then, the fireball brightness decreased from white to yellow. Finally, it disappeared slowly because of the afterburning reactions ending, and with no more energy provided to the fireball.

According to the characteristics of HMX-based aluminized thermobaric explosives, the fireball can be divided into two periods. The first period that had a short time and higher brightness was the fireball of HMX detonation. In the second period, the fireball was attributed to the burning of aluminium powders and had the characteristics of a lower brightness and longer duration. Aluminium powders were burned violently due to the blast-wave reverberations from the chamber wall. The thermal energy of the powders was transferred to the

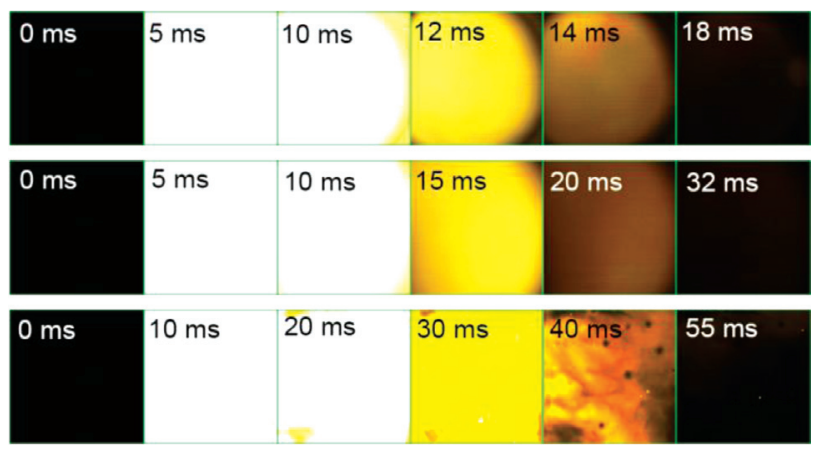

Figure 5: Growth of the fireball: a) Fireball of TBX-AP, b) Fireball of TBX-PTFE, c) fireball of TBX expanded gas, increasing the temperature of the fireball. As the aluminium powder burnt, the fireball got darker and smaller in the later stage.

The TBX-PTFE (32 ms) lasted for a long time, $14 \mathrm{~ms}$ more than TBX-AP (18 ms), but $21 \mathrm{~ms}$ less than TBX (55 ms). However, the brightness periods of TBX-PTFE and TBX-AP were similar, approximately $10 \mathrm{~ms}$, nearly $10 \mathrm{~ms}$ less than TBX. This indicated that PTFE can promote the combustion of aluminium powder, and its burning time reduced by about $18 \%$. When all the PTFE of TBX-PTFE reacted with aluminium, the remaining aluminium began to react violently with oxygen so that the fireball disappeared faster than TBX. The analysis of the fireball shows that the effect of PTFE on the afterburning duration is obvious.

\subsection{Blast characteristics}

The propagation law of blast waves in a closed space is obviously different from that in a free field. The restraint of the chamber wall causes the reflection of the blast waves and enhances the afterburning reactions of aluminized thermobaric explosives. In this paper, the pressure of the three groups of charges was recorded in the closed chamber by two PCB pressure gauges.

Three typical overpressure-time curves were selected from the recorded data, as shown in Figure 6. In consideration of the blast waves oscillating a long time in the chamber, only the overpressure within $30 \mathrm{~ms}$ was described. The overpressure had oscillation characteristics because of chamber wall reflection, chamber reflection and turbulence. The amplitude of the oscillation decreased with time, and the overpressure tended to be stable after an attenuation of $25 \mathrm{~ms}$. The sustained propagation of blast waves in the later stage was mainly maintained by the energy of aluminium afterburning. Additionally, blast waves of the TBX without oxidizer were significantly weaker.

Compared with TBX-AP and TBX, the first three wave peaks of TBX-PTFE were lower than the former. However, the trend showed the opposite trend after 20

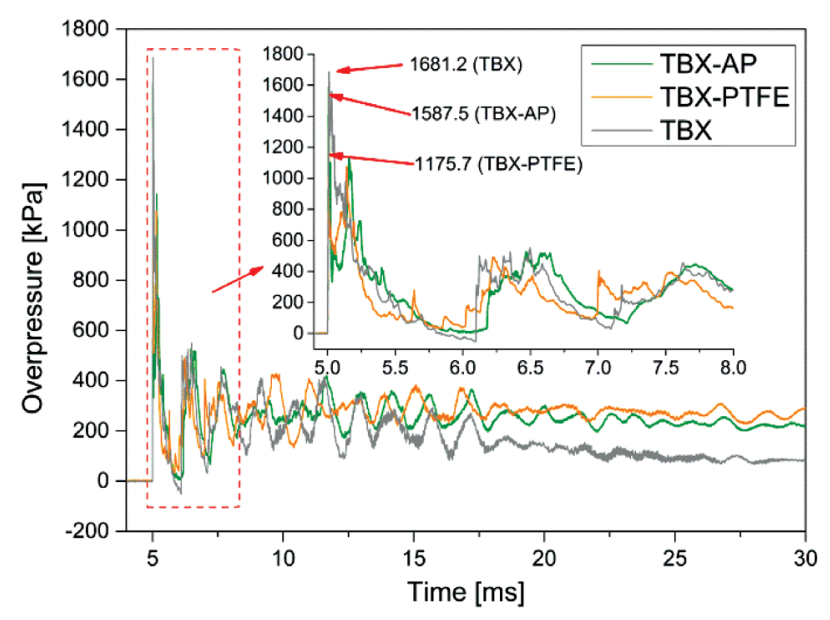

Figure 6: Typical curves of the recorded blast waves 
$\mathrm{ms}$ and continued in that way. This was because the HMX (detonation) and AP (thermal decomposition) provided more than the initial energy, while the advantage of PTFE was not obvious. It is worth noting that aluminium powders of the TBX-PTFE burned violently over time, and those chemical reactions increased the total energy of the later stages. Additionally, blast waves that kept spreading benefited from the total energy. Moreover, the TBX-PTFE had a higher blast-wave oscillation frequency, which was probably related to the more complicated $\mathrm{F}$ products in the chemical reaction of aluminium afterburning.

To explore the effect of PTFE on afterburning reactions, the specific impulse was introduced as the object of analysis. The overpressure was analysed for $60 \mathrm{~ms}$ and the total impulse was shown in Figure 7. The impulse histories showed that the impulse of aluminized thermobaric explosives increased nonlinearly in the confined space. In the first $5 \mathrm{~ms}$, the impulse of TBX-PTFE was like TBX-AP and TBX, but was slightly lower than the latter. Then, the impulse of all three continued to increase within the next $55 \mathrm{~ms}$. Obviously, the impulse of TBX-PTFE gradually exceeded that of TBX-AP and TBX. This means the energy of the afterburning reactions of the TBX-PTFE was concentrated in the late period of the explosion. This extra energy had a significant effect on the continuous propagation of blast waves. Furthermore, the reflection waves in turn strengthened the aluminium afterburning ${ }^{19}$. Consequently, the results of the total impulse showed that PTFE promoted the oxidation reactions of the aluminium powders.

The initial blast waves of the thermobaric explosives expand and propagate in the form of a sphere after the charge suspended in the centre of the chamber was initiated. Aluminium powders were oxidised to $\mathrm{Al}_{2} \mathrm{O}_{3}$ and radiated light almost instantaneously when detonation propagated. The time of the optical signal's propagation from the centre of the chamber (diameter of $1400 \mathrm{~mm}$ ) to the optical fibre sensor was almost

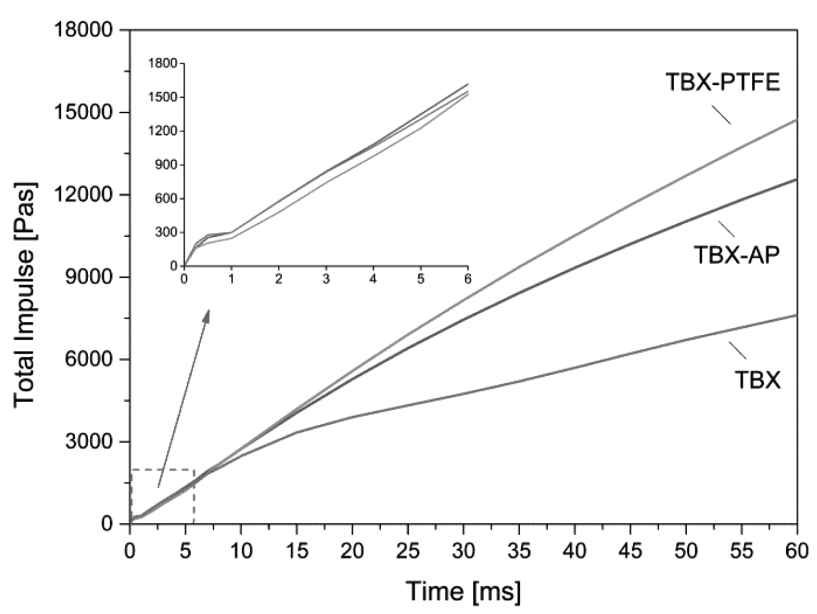

Figure 7: Impulse histories of TBX, TBX-AP and TBX-PTFE

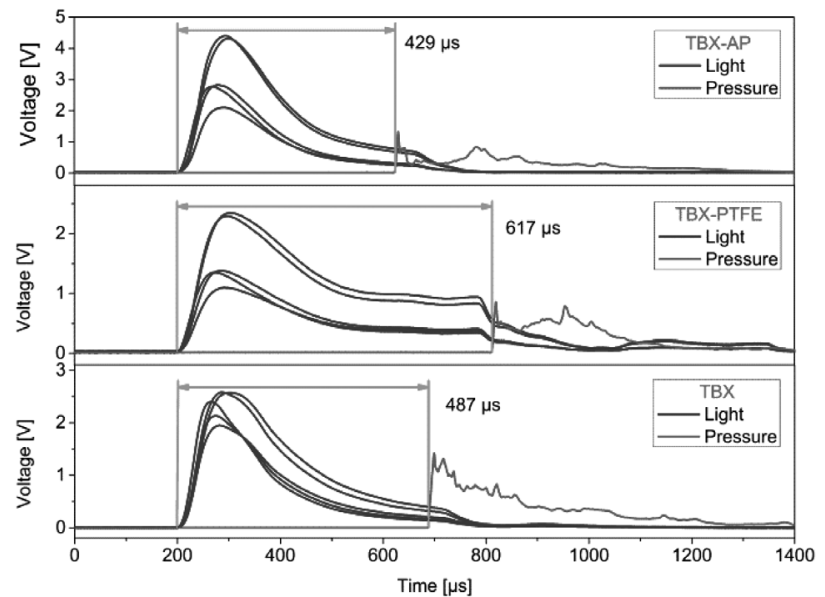

Figure 8: Recorded data for the light signal and pressure signal

negligible. Compared to the velocity of light, the blast waves slowly spread in the air. Therefore, it was assumed that the initial blast waves of these test charges were outspread at the same moment, when the first optical signal was received by the optical fibre sensor. During the tests, the position of the fibre optic sensor and PCB pressure gauges did not move. The recorded light signal and pressure signal data were shown in Figure 8.

Obviously, there was a time interval between these signals. The time interval ( $617 \mu \mathrm{s})$ of TBX-PTFE was the longest, which indicated that the propagation velocity of the initial blast wave was lower than that of TBX-AP (the time interval was $429 \mu$ s) and TBX (the time interval was $487 \mu \mathrm{s}$ ) in the air. The propagation and attenuation of the initial blast waves were closely related to the initial energy of the charge and propagation medium (air was the medium in this paper). In other words, TBX-PTFE charges contributed less initial explosion energy because of the PTFE. The small overpressure peak (shown in Figure 6) was again verified.

\section{DISCUSSION}

After the charge was detonated, the HMX first exploded and transferred heat to the surrounding particles. The temperature at this stage was low, and the aluminium particles were not enough to be gasified (gasification temperature, $2477^{\circ} \mathrm{C}$ ). However, AP can decompose violently or even explode to release energy at a very low temperature (about $400{ }^{\circ} \mathrm{C}$ ). Compared with AP, stable PTFE needs to absorb more heat to thermally decompose. The endothermic process affected the energy of the detonation reaction. Then, the detonation wave propagated in the air (that is, the initial blast wave), and particles such as aluminium and oxidant were thrown out. These particles, especially aluminum particles, continue to absorb heat when they flew outward, and gasified themselves. During the propagation of the initial blast wave, aluminium particles underwent a combustion reaction behind the wave. Moreover, the energy released 
by combustion did not affect the wave speed. Therefore, the energy of the initial blast wave was mainly derived from the detonation reaction. Obviously, the additional $10 \%$ of AP and HMX contributed more energy than PTFE. The result was that the blast waves signals of TBX and TBX-AP were first recorded by the gauges before the TBX-PTFE, and their peak overpressure was also higher, as shown in Figure 6 and Figure 8. Contrary to the expected results, the time interval of TBX was longer than that of TBX-AP, which might be due to the deviation of the charge from the centre of the spherical chamber.

Figure 8 also showed that when the initial blast wave touched the sensitive surface of the gauges, the afterburning reactions had come to an end. Therefore, the combustion of aluminium particles mainly contributed energy to subsequent blast waves and fireballs, and affected them. The thermal decomposition products of AP were $\mathrm{O}_{2}, \mathrm{H}_{2} \mathrm{O}$ and $\mathrm{Cl}_{2}$, increased the concentration of O. While PTFE continued to absorb heat, the combustion reaction lagged the former. After PTFE was heated to a certain degree, it would first be decomposed into active small molecules such as $\mathrm{C}_{2} \mathrm{~F}_{4}$. In the anaerobic stage of the post-combustion reaction, $\mathrm{C}_{2} \mathrm{~F}_{4}$ reacted with $\mathrm{Al}$ to produce $\mathrm{AlF}_{3}$ and $\mathrm{C}$. The oxygen in the air was drawn into the explosion field, which was the aerobic stage, the products were AlF3 and $\mathrm{CO}_{2} \cdot{ }^{20}$ For TBX-PTFE, the amount of $\mathrm{Al}_{2} \mathrm{O}_{3}$ produced was reduced because of a part of the aluminium reacted with $\mathrm{F}$. This process caused the light radiation intensity of $\mathrm{Al}_{2} \mathrm{O}_{3}$ to be lower than the other two, thereby reduced the fireball temperature, which was reflected in Figure 4.

After that, the remaining aluminium continued to react with $O$. According to the study results of papers, ${ }^{11,21}$ the aluminium of the thermobaric explosive was not completely burned, and about $62.0 \%$ of the $\mathrm{O}$ in the products $\left(\mathrm{Al}_{2} \mathrm{O}_{3}\right)$ came from the $\mathrm{O}_{2}$ in the air. Therefore, PTFE was equivalent to consuming incompletely burned aluminium and contributed energy through this process. The additional energy was reflected in the extended duration of the fireball's high temperature, and the total impulses were enhanced. In contrast, in the explosion field of TBX, the concentration of oxidizing substances $\left(\mathrm{O}_{2}, \mathrm{H}_{2} \mathrm{O}, \mathrm{CO}\right.$, etc. $)$ was lower, resulting in a long burning time for the aluminium particles, but the afterburning reactions could not contribute much energy. These results can be seen from Figure 5 and Figure 7. To summarize, PTFE had certain advantages in promoting the afterburning reaction of thermobaric explosive. It could increase the total energy of the explosion and enhance the pressure effect and the thermal effect.

\section{CONCLUSIONS}

The investigation showed that the optical radiation of $\mathrm{Al}_{2} \mathrm{O}_{3}$ is an effective method to describe the fireball temperature, and the method is highlighted. The PTFE increases the duration of the fireball temperature above $1000 \mathrm{~K}$, and the time of converting $\mathrm{Al}$ to $\mathrm{Al}_{2} \mathrm{O}_{3}$ is extended to nearly $200 \mu \mathrm{s}$. The afterburning reactions of aluminium powder were promoted because of PTFE, and the duration time of the fireball reduced by about $18 \%$. The PTFE has no significant effect on increasing the initial energy and overpressure of the explosion. Nevertheless, it can increase the total energy and total impulse of the shock wave. In addition, the attenuation of the shock wave takes more time.

\section{Acknowledgements}

This work was financially supported by the National Natural Science Foundation of China under No. 11702142. Meanwhile, thanks to Ju Huang and Xiao-wen Hong for modified this paper, and thanks to Zhiwei Han who had offered help to the explosion text of this work.

\section{REFERENCES}

${ }^{1}$ Q. Zhang, C. H. Bai, H. Y. Dang, H. Yan, Critical Ignition Temperature of Fuel-air Explosive, Def. Sci. J., 54 (2004), 469-474, doi:10.14429/DSJ.54.2060

${ }^{2}$ A. L. Michael, Study on the effect of nuclear earthpenetrator weapon and other weapons, Washington: The National Academy of Sciences, 2005, doi:10.17226/11282

${ }^{3}$ M. A. Cooper, M. J. Kaneshige, R. J. Pahl, Methods for evaluating Aluminized RDX explosives. Proceeding of the $13^{\text {th }}$ international detonation symposium, Norfolk, Virginia, 2006

${ }^{4}$ W. A. Trzciński, K. Barcz, J. Paszula, S. Cudzilo, Investigation of Blast Performance and Solid Residues for Layered Thermobaric Charges, Propellants Explos. Pyrotech., 39 (2014), 40, doi:10.1002/ PREP.201300011

${ }^{5}$ G. Young, C. A. Stoltz, D. H. Mayo, C. W. Roberts, C. L. Milby, Combustion behaviors of them Solid Fuels based on PTFE/Boron Mixtures, Combust. Sci. Technol., 185 (2013), 1261-1280, doi:10.1080/00102202.2013.787417

${ }^{6}$ P. Verma, J. G. Bhujbal, R. B. Ghavate, S. Darekar, Check Effect of them marketers Binders Mechanical And Ballistic the Properties of them Boron-Viton based Fuel Rich Propellantf, Aip Conference, 153 (2013), 1248-1249, doi:10.1063/1.4810693

${ }^{7}$ Q. L. Yan, S. Zemana, A. Elbeih, Thermal behaviors and Decomposition Kinetics of them Viton A Bonded Explosives Containing Attractive Cyclic Nitramines, Thermochimica Acta, 562 (2013), 56-64, doi:10.1016/J.TCA.2013.03.041

${ }^{8}$ G. Young, C. W. Roberts, C. A. Stoltz, Ignition and Combustion Enhancement of them Boron With Polytetrafluoroethylene, Journal of Propulsion and Power, 31 (2015), 386-392, doi:10.2514/1.B35390

${ }^{9}$ M. L. Chan, G. W. Meyers, Advanced thermobaric explosive compositions, U. S. 6955732. B1 2005

${ }^{10}$ M. F. Gogulya, M. N.Makhov, M. A. Brazhnikov, A. Yu. Dolgoborodov, Detonation-like processes in Teflon/Al-based explosive mixtures, $13^{\text {th }}$ International Detonation Symposium, Norfolk, VA, 2006

${ }^{11}$ L. Maiz, W. A. Trzciński, M. Szala, J. Paszula, Studies of Confined Explosions of Composite Explosives and Layered Charges, Cent. Eur. J. Energ. Mater, 13 (2016), 957-977, doi:10.22211/CEJEM/ 65075 


\section{W. XIAO et al.: EFFECT OF PTFE ON A CONFINED EXPLOSION OF HMX-BASED THERMOBARIC EXPLOSIVES}

${ }^{12}$ L. Maiz, W. A. Trzciński, M. Szala, Preparation and Testing of Thermobaric Composites, $18^{\text {th }}$ Seminar on New Trends in Research of Energetic Materials, Pardubice, Czech Republic, 2015, 705-715

${ }^{13}$ S. Goroshin, J. Mamen, A. Higgins, T. Bazyn, N. Glumac, H. Krierb, Emission spectroscopy of flame fronts in aluminum suspensions, Proc. Combust. Inst., 31 (2007), 2011-2019, doi:10.1016/J.PROCI. 2006.07.175

${ }^{14}$ W. K. Lewis, C. G. Rumchik, P. B. Broughton, C. M. Lindsay, Time-resolved spectroscopic studies of aluminized explosives: chemical dynamics and apparent temperatures, J. Appl. Phys., 111 (2012), 014903, doi:10.1063/1.3673602

${ }^{15} \mathrm{~A}$. Snelson, Infrared spectrum of $\mathrm{AlF}_{3}, \mathrm{Al}_{2} \mathrm{~F}_{6}$, and $\mathrm{AlF}$ by matrix isolation, J. Phys. Chem., 71 (1967), 3202-3207, doi:10.1021/ j100869a011

${ }^{16}$ J. B. Deng, Study of the damage effects of four thermobaric explosives, Nanjing University of Science \& Technology, 2013 (in Chinese)

${ }^{17}$ J. R. Carney, J. M. Lightstone, T. P. McGrath II, R. J. Lee, Fuel-rich explosive energy release: oxidizer concentration dependence, Propellants Explos. Pyrotech., 34 (2009), 331-339, doi:10.1002/ PREP.200800037
${ }^{18}$ K. McNesby, B. E. Homan, J. J. Ritter, Z. R. Quine, Afterburn ignition delay and shock augmentation in fuel rich solid explosives, Propellants Explos. Pyrotech., 35 (2010), 57-65, doi:10.1002/PREP. 200800084

${ }^{19}$ L. Maiz, W. A. Trzciński, J. Paszula, Semi-closed Investigations of New Aluminized Thermobaricand Enhanced Blast Composites, Propellants Explos. Pyrotech., 42 (2017), 1-8, doi:10.1002/PREP. 201700062

${ }^{20}$ M. Losada, S. Chaudhuri, Theoretical Study of Elementary Steps in the Reactions between Aluminum and Teflon Fragments under Combustive Environments, J. Phys. Chem. A, 113 (2009), 5933-5941, doi:10.1021/jp810156j

${ }^{21}$ J. E. Monat, J. R. Carney, J. M. Lightstone, N. Shimizu, Determining the source of oxygen in post-detonation combustion of aluminum, AIP Conf. Proc., 1426 (2012), 410-413, doi:10.1063/1.3686305 